\title{
Appliance of Simulation Modelling in Wastewater Treatment
}

\author{
Lovorka Gotal Dmitrović, Mario Lešina, and Hrvoje Selec
}

\begin{abstract}
A complex adaptive engineering wastewater treatment system for drinking water quality was developed, based on data from two real-world systems. Each component, which is present in the real situation with a water purification system, consists of a series of physical, chemical and / or biological purifiers according to their purpose, i.e. the purification value through the purification process. Developed conceptual model is a computer variables model uses randomly chosen values from the theoretical probability distribution of the variable applied. For the validation of the model, considering that the distributions are asymmetrical non-Gaussian distributions, a non-parametric test was applied. Methodology proposed in the paper is based on the simulation modelling. The design of a complex adaptive engineering system for the purification of communal water on the quality of drinking water is the fundamental outcome of this research, starting from its conceptual level until the realization of the described system at project level.
\end{abstract}

Index Terms-Asymmetrical non-Gaussian distribution, complex adaptive engineering system, simulation modelling, wastewater treatment.

\section{INTRODUCTION}

Actual data was collected for a period of 5 years of actual waste water treatment systems on surface water quality (system 1) and surface water treatment systems in drinking water (system 2). The main component of the waste water treatment system is a bioaerating tank, and the surface water treatment system consists of a floculator and a sand filter. The weekly mean value of the data was calculated, while the Missing data belongs to Missing at random (MAR)), the sample remains representative [1]. For the data processing the recommended deletion method is Listwise deletion, which is only used for the complete rows of table data [2], [3].

Values Missing at random (MAR) is an alternative to data Missing completely at random (MCAR), which occurs when the missing data is relating to a particular variable, like for example an accidentally skipped answer from a questionnaire [4]. The interesting fact is that the Listwise Deletion Method, which is the simplest method, provides very good matching results with the probability distributions [2]. This method, in non-Gaussian probability distribution, closely follows the observed distributions, with the exception of a deviation from the actual value at the peak of the

Manuscript received May 13, 2019; revised September 12, 2019.

Lovorka Gotal Dmitrović is with the University North, Varazdin, Croatia (e-mail: lgotaldmitrovic@unin.hr).

Mario Lešina is with the University North, Varazdin, Croatia.

Hrvoje Selec is with the University North, Varazdin, Croatia.

\section{distribution.}

For the purposes of this study, the actual, empirical data was collected and used from the non-Gaussian probability distribution of the observed real system. These are asymmetric probability distributions with a tail, as is often the case in modelling complex technical systems [5]. To achieve the authenticity of the model, it is necessary to incorporate the actual system behaviour using the weekly mean concentration values, which were determined from the typical theoretical distribution of probability for every particular event frequency. Using the applications Stat::Fit simulation packages Servicemodel v4.2., the characteristic theoretical distribution of the organic matter concentration, as well as the basic characteristics of descriptive statistics, were obtained at each checkpoint (at the entrance and the exit). These data are shown in Table I.

TABLE I: DESCRIPTIVE STATISTICS AND CHARACTERISTIC THEORETICAL

\begin{tabular}{|c|c|c|c|c|c|}
\hline \multicolumn{6}{|c|}{ PROBABILITY DISTRIBUTION IN THE CONTROL POINT } \\
\hline & $\begin{array}{c}\text { The entrance } \\
\text { to the } \\
\text { bioaeration } \\
\text { tank }\end{array}$ & $\begin{array}{c}\text { Output from } \\
\text { to the } \\
\text { bioaeration } \\
\text { tank }\end{array}$ & $\begin{array}{l}\text { The entrance } \\
\text { to the } \\
\text { floculator }\end{array}$ & $\begin{array}{l}\text { Output from to } \\
\text { the floculator / } \\
\text { The entance to } \\
\text { the sand filter }\end{array}$ & $\begin{array}{l}\text { Output from } \\
\text { to the filter }\end{array}$ \\
\hline $\begin{array}{l}\text { Theoretical } \\
\text { distribution }\end{array}$ & $\begin{array}{c}\text { Log-normal } \\
(-207 ; 6.63 ; \\
0.483)\end{array}$ & \begin{tabular}{|c|} 
Log-normal \\
$(4.68 ; 3.28 ;$ \\
$0.576)$
\end{tabular} & $\begin{array}{c}\text { Log-normal } \\
(1.83 ; 0.009 ; \\
0.562)\end{array}$ & $\begin{array}{c}\text { Log-logistic } \\
(1.28 ; 4 ; 0.697)\end{array}$ & \begin{tabular}{|c} 
Log-logistic \\
$(0.904 ; 5.22 ;$ \\
$0.657)$
\end{tabular} \\
\hline Data points & 261 & 260 & 258 & 258 & 256 \\
\hline $\begin{array}{c}\text { Minimum } \\
\left(\mathrm{mgO}_{2} / \mathrm{l}\right)\end{array}$ & 36.1429 & 9.71429 & 2.01 & 1.42 & 1.164 \\
\hline $\begin{array}{c}\text { Maximum } \\
\left(\mathrm{mgO}_{2} / \mathrm{l}\right)\end{array}$ & 1947.43 & 146.857 & 6.275 & 4.1675 & 2.892 \\
\hline $\begin{array}{c}\text { Mean } \\
\left(\mathrm{mgO}_{2} / \mathrm{l}\right)\end{array}$ & 641.144 & 36.0885 & 3.00745 & 2.05226 & 1.59937 \\
\hline $\begin{array}{c}\text { Median } \\
\left(\mathrm{mgO}_{2} / \mathrm{l}\right)\end{array}$ & 548.429 & 32 & 2.806 & 1.985 & 1.58 \\
\hline $\begin{array}{c}\text { Mode } \\
\left(\mathrm{mgO}_{2} / \mathrm{l}\right)\end{array}$ & 243.786 & 24.1429 & 2.63733 & 2.018 & 1.647 \\
\hline $\begin{array}{l}\text { Standard } \\
\text { deviation } \\
\left(\mathrm{mgO}_{2} / \mathrm{l}\right)\end{array}$ & 403.587 & 19.9632 & 0.709562 & 0.392285 & 0.255514 \\
\hline $\begin{array}{c}\text { Variance } \\
\left(\left(\mathrm{mgO}_{2} / \mathrm{l}\right)^{2}\right)\end{array}$ & 162882 & 398.529 & 0.503478 & 0.153887 & 0.0652876 \\
\hline $\begin{array}{c}\text { Coefficient } \\
\text { of variation } \\
\left(\mathrm{mgO}_{2} / \mathrm{l}\right)\end{array}$ & 62.9479 & 55.3174 & 23.5934 & 19.1148 & 15.9759 \\
\hline
\end{tabular}

After determining the family of curves, an evaluation of the data collection with the selected distribution was determined, with the tests: $\chi 2$ - test, Kolmogorov - Smirnov test and Anderson - Darling test. The results of the data collection with the selected distribution are shown in Table II.

\section{DeVelopment OF The Teal SyStem Models}

The models of both systems were first designed as conceptual models using the activity cycle diagrams (Fig. 1 and Fig. 2). 


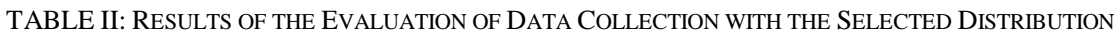

\begin{tabular}{|c|c|c|c|c|c|c|c|c|}
\hline & \multirow[t]{2}{*}{ Distribution } & \multirow[t]{2}{*}{ Probability } & \multicolumn{2}{|c|}{$\chi^{2}$} & \multicolumn{2}{|c|}{$\begin{array}{c}\text { Kolmogorov - Smirnov } \\
\text { test }\end{array}$} & \multicolumn{2}{|c|}{ Anderson - Darling test } \\
\hline & & & $p$-value & $\mathrm{H}_{0} / \mathrm{H}_{1}$ & $p$-value & $\mathrm{H}_{0} / \mathrm{H}_{1}$ & $p$-value & $\mathrm{H}_{0} / \mathrm{H}_{1}$ \\
\hline $\begin{array}{l}\text { The entrance to the } \\
\text { bioaeration tank }\end{array}$ & $\begin{array}{c}\text { Log-normal } \\
(-207 ; 6,63 ; 0,483)\end{array}$ & 0,95 & 0,739 & $\mathrm{H}_{0}$ & 0,541 & $\mathrm{H}_{0}$ & 0,514 & $\mathrm{H}_{0}$ \\
\hline $\begin{array}{l}\text { The entrance to the } \\
\text { floculator }\end{array}$ & $\begin{array}{c}\text { Log-normal }(1,83 ; \\
0,00895 ; 0,562) \\
\end{array}$ & 0,95 & 0,889 & $\mathrm{H}_{0}$ & 0,803 & $\mathrm{H}_{0}$ & 0,904 & $\mathrm{H}_{0}$ \\
\hline $\begin{array}{l}\text { The entance to the sand } \\
\text { filter }\end{array}$ & $\begin{array}{c}\text { Log-logistic }(1,28 ; 4 ; \\
0,697)\end{array}$ & 0,95 & 0,77 & $\mathrm{H}_{0}$ & 0,988 & $\mathrm{H}_{0}$ & 0,999 & $\mathrm{H}_{0}$ \\
\hline
\end{tabular}

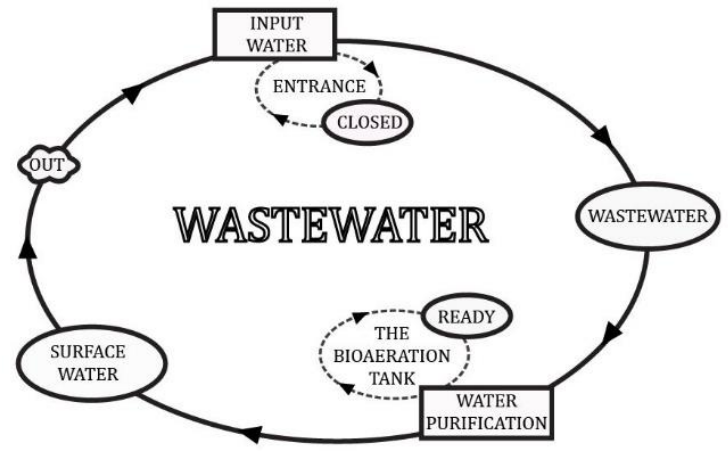

Fig. 1. ACD system 1.

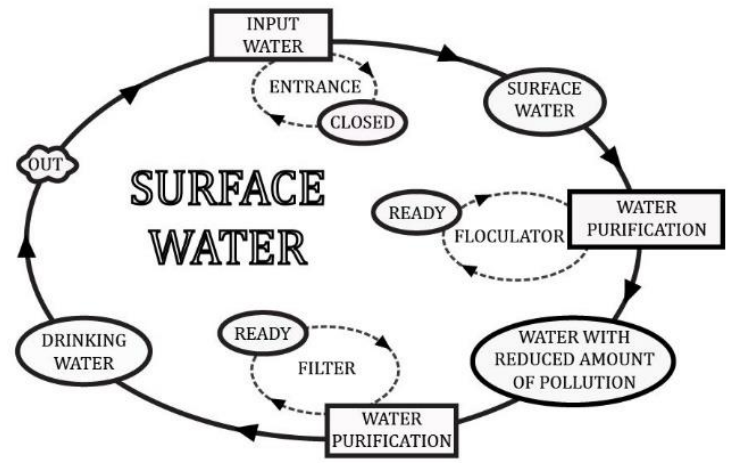

Fig. 2. ACD system 2.

The mathematical model of real system was created, based on the system of differential-difference equations. The Runge-Kutta method was used to solve equations system.

Mathematical modeling framework was applied to develop the model component of water treatment system using differential and difference-differential equations. This occurs for the component according to the following reaction (1) written as differential equation [2].

$$
S=(D \cdot(I-S)-d S / d t) /(K+D)
$$

whereas:

$I$ - input concentration in system $(\mathrm{mg} / \mathrm{l})$,

$S$ - output concentration in system $(\mathrm{mg} / \mathrm{l})$, $d S / d t$ - changes in water cleanliness $(\mathrm{mg} / \mathrm{l} / \mathrm{h})$,

$K-$ goodness of purification $(1 / \mathrm{h})$,

$1 / D$ - time in the water holding in components (h).

The changes in water cleanliness are:

$$
d S / d t=D \cdot(I-S)-S \cdot(K+D)
$$

Initial equation in system component, according to equation (2), is:

$$
\begin{gathered}
d S / d t=D \cdot(I-S)-K \cdot S \\
d S / d t=(-D-K) \cdot S+D \cdot I \\
d S / d t+(D+K) \cdot S=D \cdot I
\end{gathered}
$$

Written in the form of difference equations:

$$
S(t+\Delta t)=S(t)+D \cdot(I-S) \cdot \Delta t-K \cdot S \cdot \Delta t
$$

In the component, the difference equation was generated by using the Runge-Kutta method. Assuming that $t(0)=0$, that is, at time $t(0)$, the output $S(0)=0$, according to the Runge-Kutta (IV) method, applies:

$$
S\left(t_{i+1}\right)=S\left(t_{i}+\Delta t_{i}\right)=S\left(t_{i}\right)+1 / 6\left[K_{1}{ }^{(i)}+K_{2}{ }^{(i)}+K_{3}{ }^{(i)}+K_{4}{ }^{(i)}\right]
$$

whereas:

$$
\begin{gathered}
K_{1}{ }^{(i)}=\Delta t_{i} \cdot F\left(t_{i}, S\left(t_{i}\right)\right) \\
F\left(t_{i}, S\left(t_{i}\right)\right)=D \cdot\left(I\left(t_{i}\right)-S\left(t_{i}\right)-K\left(t_{i}\right) \cdot S\left(t_{i}\right)\right. \\
K_{2}^{(i)}=\Delta t_{i} \cdot F\left(t_{i}+\Delta t_{i} / 2, S\left(t_{i}\right)+1 / 2 K_{1}^{(i)}\right) \\
F(t, S)=(-D-K) \cdot S+D \cdot I \\
F\left(t_{i}+\Delta t_{i} / 2, S\left(t_{i}\right)+1 / 2 K_{1}{ }^{(i)}\right)= \\
=\left(-D-K\left(t_{i}+\Delta t_{i} / 2\right)\right) \cdot\left[S\left(t_{i}\right)+1 / 2 K_{1}^{(i)}+D \cdot \mathrm{I}\left(t_{i}+\Delta t_{i} / 2\right)\right] \\
K_{3}^{(i)}=\Delta t_{i} \cdot F\left(t_{i}+\Delta t_{i} / 2, S\left(t_{i}\right)+1 / 2 K_{2}{ }^{(i)}\right) \\
F\left(t_{i}+\Delta t_{i} / 2, S\left(t_{i}\right)+1 / 2 K_{2}^{(i)}\right)= \\
=\left(-D-K\left(t_{i}+\Delta t_{i} / 2\right)\right) \cdot\left[S\left(t_{i}\right)+1 / 2 K_{2}{ }^{(i)}+D \cdot I\left(t_{i}+\Delta t_{i} / 2\right)\right. \\
K_{4}^{(i)}=\Delta t_{i} \cdot F\left(t_{i}+\Delta t_{i} / 2, S\left(t_{i}\right)+K_{3}{ }^{(i)}\right) \\
F\left(t_{i}+\Delta t_{i}, \mathrm{~S}\left(t_{i}\right)+K_{3}^{(i)}\right)= \\
=\left(-D-K\left(t_{i}+\Delta t_{i}\right)\right) \cdot\left[S\left(t_{i}\right)+K_{3}^{(i)}+D \cdot I\left(t_{i}+\Delta t_{i}\right)\right]
\end{gathered}
$$

The goodness of purification isn't constant and it is presented as a theoretical probability distribution:

$$
K=f(S) / S=\{[(I-S) \cdot D]-d S / d t\} / S
$$

Retention time $(1 / D)$ is obtained from the expression:

$$
1 / \mathrm{D}=\mathrm{V} / Q
$$

whereas:

$V$ - volume component $\left(\mathrm{m}^{3}\right)$ and 
$Q$ - flow rate of water through a component $\left(\mathrm{m}^{3} /\right.$ day).

For the values of goodness (quality) of the purification, using the Stat:Fit application from the Service Model v4.2 simulation package. Characteristic theoretical distribution and the basic characteristics of descriptive statistics are determined. The data are presented in Table III.

Statistics are determined. The data are presented in Table III.

TABLE III: DESCRIPTIVE STATISTICS AND CHARACTERISTIC THEORETICAL DISTRIBUTION FOR PURIFICATION GOODNESS

\begin{tabular}{|c|c|c|c|}
\hline & $\begin{array}{c}\text { Goodness of purification in the } \\
\text { bioaction tank }\end{array}$ & $\begin{array}{c}\text { Goodness of purification in the } \\
\text { floculator }\end{array}$ & $\begin{array}{c}\text { Goodness of purification in the } \\
\text { filter }\end{array}$ \\
\hline Theoretical distribution & $\begin{array}{c}\text { Log-normal } \\
(-21.3 ; 3.63 ; 0.239)\end{array}$ & $\begin{array}{c}\text { Log-normal } \\
(-0.69 ; 0.131 ; 0.223)\end{array}$ & $\begin{array}{c}\text { Log-logistic } \\
(-1.75 ; 21.9 ; 2.02)\end{array}$ \\
\hline Data points & 260 & 257 & 255 \\
\hline Minimum & 0.856716 & -0.141322 & -0.0703839 \\
\hline Maximum & 55.7228 & 1.31866 & 0.875328 \\
\hline Mean & 17.504 & 0.478442 & 0.287394 \\
\hline Median & 15.8148 & 0.444995 & 0.272152 \\
\hline Mode & 15.1228 & 0.288617 & 0.26112 \\
\hline Standard deviation & 9.35954 & 0.265449 & 0.167315 \\
\hline Variance & 87.6011 & 0.0704631 & 0.0279944 \\
\hline
\end{tabular}

After determining the family of the curve, the estimation of data collection with the selected distribution was determined, the tests: $\chi 2$ - square test, Kolmogorov - Smirnov test and Anderson - Darling test. The results of the data collection with the selected distribution are shown in Table IV.

TABLE IV: RESULTS OF THE COMPATIBILITY OF PURIFICATION GOODNESS WITH THE SELECTED DISTRIBUTION

\begin{tabular}{|c|c|c|c|c|c|c|c|c|}
\hline & \multirow[t]{2}{*}{ Distribution } & \multirow[t]{2}{*}{ Probability } & \multicolumn{2}{|c|}{$\chi^{2}$} & \multicolumn{2}{|c|}{$\begin{array}{l}\text { Kolmogorov - } \\
\text { Smirnov test }\end{array}$} & \multicolumn{2}{|c|}{$\begin{array}{c}\text { Anderson - Darling } \\
\text { test }\end{array}$} \\
\hline & & & $\mathrm{p}$-value & $\mathrm{H}_{0} / \mathrm{H}_{1}$ & $\mathrm{p}$-value & $\mathrm{H}_{0} / \mathrm{H}_{1}$ & $\mathrm{p}$-value & $\mathrm{H}_{0} / \mathrm{H}_{1}$ \\
\hline $\begin{array}{l}\text { Goodness of purification in the } \\
\text { bioaeration tank }\end{array}$ & $\begin{array}{c}\text { Log-normal } \\
(-21.3 ; 3.63 ; 0.239)\end{array}$ & 0,95 & 0,0728 & $\mathrm{H}_{0}$ & 0,675 & $\mathrm{H}_{0}$ & 0,655 & $\mathrm{H}_{0}$ \\
\hline $\begin{array}{l}\text { Goodness of purification in the } \\
\text { floculator }\end{array}$ & $\begin{array}{c}\text { Log-normal } \\
(-0.69 ; 0.131 ; 0.223)\end{array}$ & 0,95 & 0,982 & $\mathrm{H}_{0}$ & 0,991 & $\mathrm{H}_{0}$ & 0,989 & $\mathrm{H}_{0}$ \\
\hline $\begin{array}{l}\text { Goodness of purification in the } \\
\text { filter }\end{array}$ & $\begin{array}{c}\text { Log-logistic } \\
(-1.746 ; 21.877 ; 2,024)\end{array}$ & 0,95 & 0,654 & $\mathrm{H}_{0}$ & 0,949 & $\mathrm{H}_{0}$ & 0,984 & $\mathrm{H}_{0}$ \\
\hline
\end{tabular}

The computer model was created in Powersim Constructor Version 2.51. The components of real systems where the water is purified from organic matter are: a bioaction tank, a float and filter.

The computer model for each system variable uses randomly selected values from the theoretical probability distribution of that variable (Table I and Table III). According to the expression (2), the Runge-Kutta method calculates a change in water purity $(\mathrm{dS} / \mathrm{dt})$, i.e. mass concentration at the output (S).

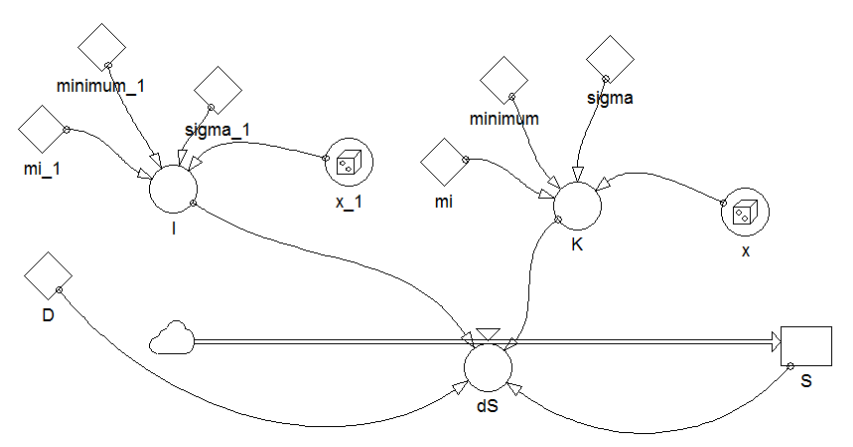

Fig. 3. Computer model for each component of purification system.

By evaluating the simulation model, it is examined whether the simulation model adequately represents the actual system. The actual output values with the output from the model are compared. Since distributions are not included in the Gaussian curve family according to Petz et al., 2012, or that are asymmetric, nonparametric methods are used for the test (sometimes referred to as "free from distribution") [6] Since the two independent samples were used, the test sums (Mann-Whitney U-test) were used. The values shown in Table $\mathrm{V}$ are obtained. The same table shows the minimum, maximum and mean values for the real mass concentration and the mass concentration obtained by the model.

\begin{tabular}{|c|c|c|c|c|}
\hline & & Real value & Model value & $\begin{array}{c}\text { Mann-Whitney } \\
\text { U test }\end{array}$ \\
\hline \multirow[t]{3}{*}{ Floculator } & Minimum & 1.42 & 0.66 & \multirow{3}{*}{$\begin{array}{l}\mathrm{H}_{0} \\
\mathrm{Z}=1.567208 \\
\mathrm{p}=0.117067\end{array}$} \\
\hline & Maximum & 4.16 & 3.5 & \\
\hline & Mean & 2.06 & 2.09 & \\
\hline \multirow[t]{3}{*}{ Filter } & Minimum & 1.16 & 1.06 & \multirow{3}{*}{$\begin{array}{l}\mathrm{H}_{0} \\
\mathrm{Z}=-1.32451 \\
\mathrm{p}=0.185335\end{array}$} \\
\hline & Maximum & 2.89 & 2.83 & \\
\hline & Mean & 1.60 & 1.64 & \\
\hline \multirow[t]{2}{*}{ Bioaerator } & Minimum & 9.71 & 10.09 & \multirow{2}{*}{$\begin{array}{l}\mathrm{H}_{0} \\
Z=-1.62996 \\
p=0.103106\end{array}$} \\
\hline & Maximum & 146.85 & 135.03 & \\
\hline
\end{tabular}

Test confirmed that there was no statistically significant difference between the range of real values and the range of values obtained by the model.

\section{Simulation EXPERIMENT}

After simulation models of real systems have been developed, the simulated model of the integrated system - an improved model is formed by defining the transition point (waste water in drinking water). The integrated system was 
developed by merging the models of both real systems. The activity cycle diagrams of this system is shown in Fig. 4.

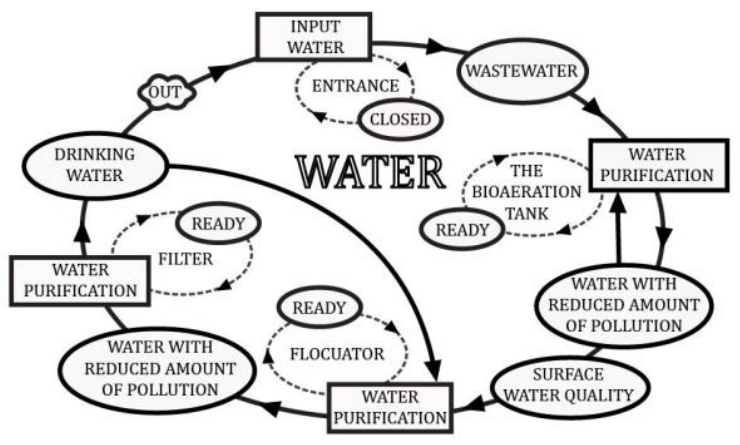

Fig. 4. Integrated system.

There must be at least two control posts for the wastewater treatment system for drinking water. Since the upper limit (UCL) is the prescribed value, control maps are created and certain warning areas and critical events are defined, i.e. a safety and warning band is defined, thus setting the self-regulation of the model. According to the Croatian legislation, the limit value for the concentration of organic matter in surface water discharge are $125 \mathrm{mgO}_{2} / \mathrm{L}$. At another metering point, exit from the purification system, the water quality must correspond to the quality of the drinking water and the limit value is $5.0 \mathrm{mgO}_{2} / \mathrm{L}$. According to these values, checkpoints were created for metering points: measurement point 1 - transition point, metering point 2 exit from the system. The central line is at $\mathrm{x}$ axis, i.e. in $\mathrm{y}=0$, while the limit is taken from the legal regulation as the upper bound. Control charts are shown in Fig. 5 and Fig. 6.

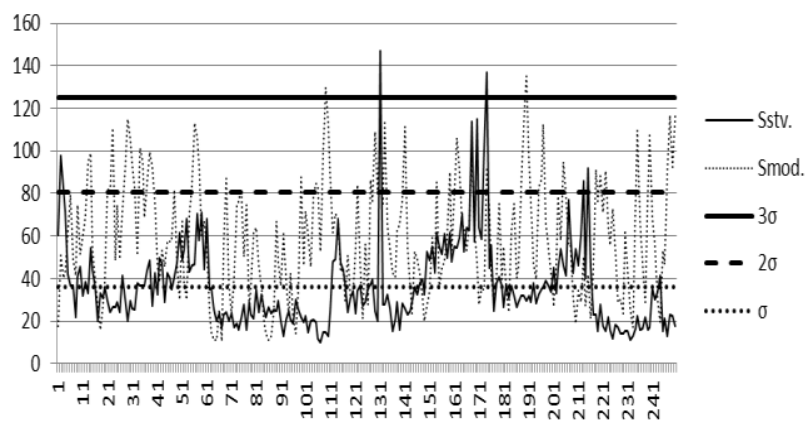

Fig. 5. Control chart of metering point 1 .

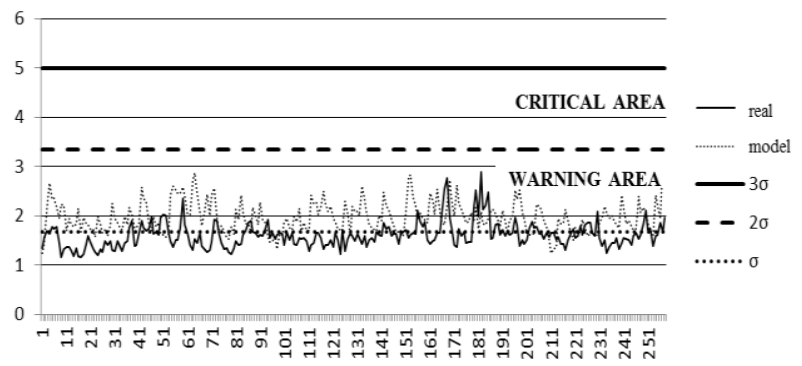

Fig. 6. Control chart of metering point 2 .

\section{The Result AND Discussion}

Fig. 5 and 6 show the values of the actual system and the model with the control charts. As visible from the charts at both measuring points, concentration values are occasionally the critical area. Therefore, a system is proposed in which the water is purified from the organic matter by double passing through a bioaeration tank and double passed through a flocculator and filter (Fig. 7). The double purification results are shown in Fig. 8.

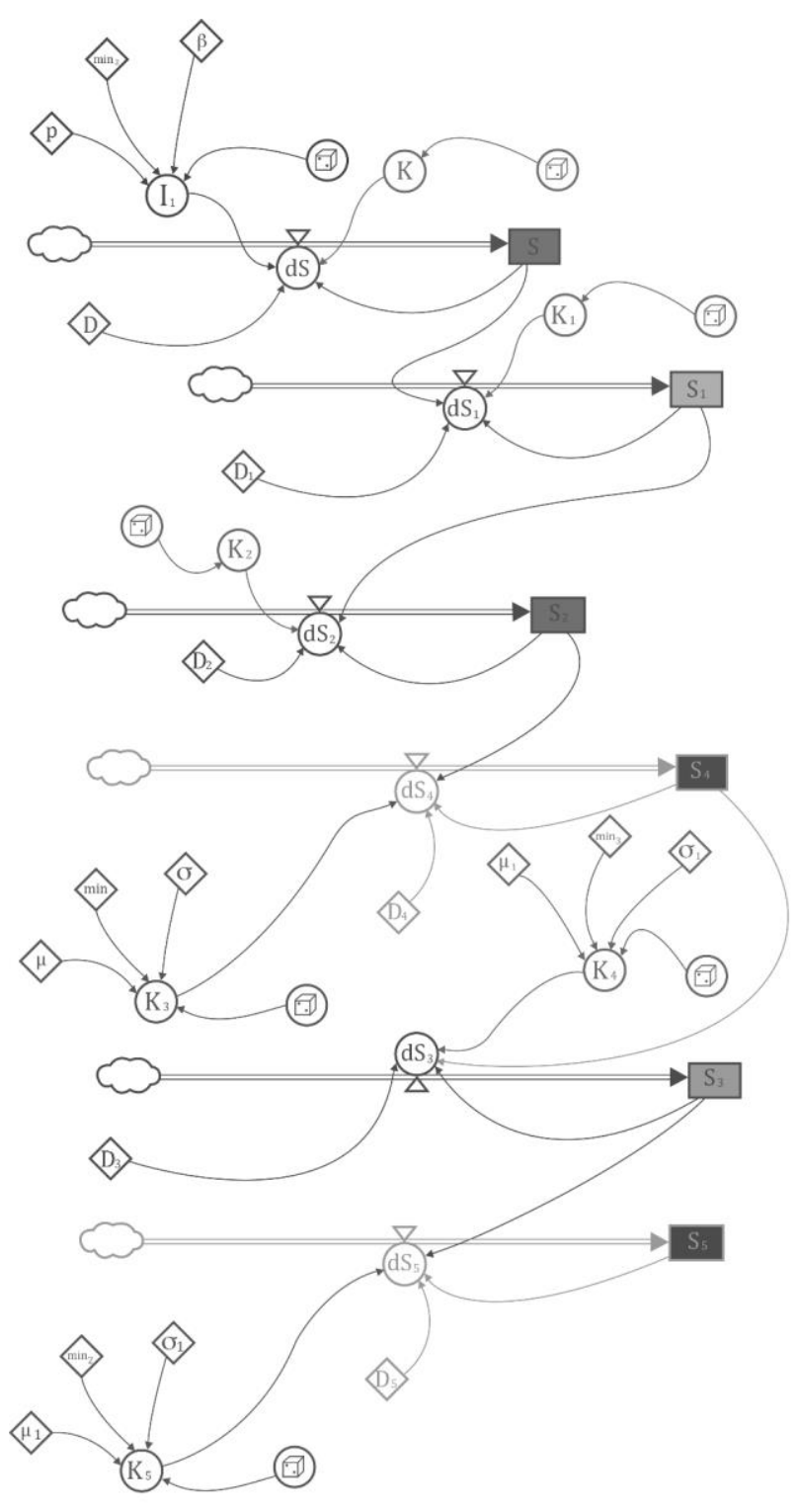

Fig. 7. Wastewater treatment in drinking water.

Fig. 8 shows the values of organic matter concentrations at the output from bioaeration tank 2 (transition point) and filter 2 (system exit).

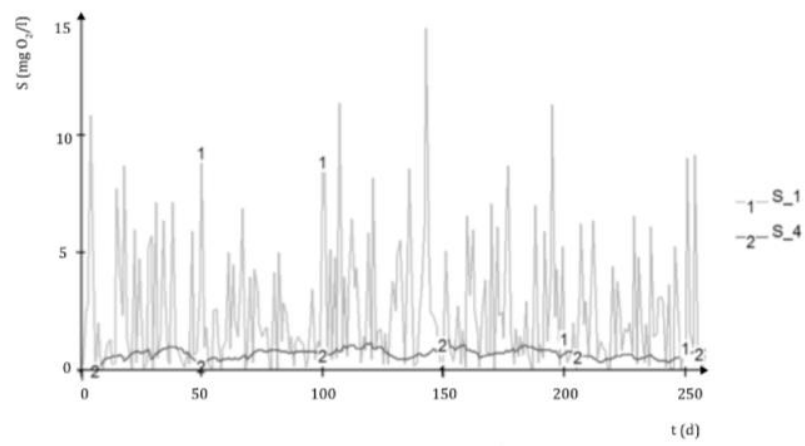

Fig. 8. Comparison of the simulated concentrations of organic matter from bioaeration tank 2 (S 1) and from filter 2 (S 4). 


\section{CONCLUSION}

The features of the actual systems are transferred to a simulation model under different operating conditions. Adaptive simulation model is created using conceptualisation and parameterization. Adaptive models enable portability in terms of the application of such systems to other locations, i.e. with different values of input concentrations of contamination. Innovative model has been developed to acquire knowledge about wastewater treatment in drinking water on large and inexpensive systems. Simulation modelling methods contribute significantly to the preservation of the environment and human health.

Research goals have been achieved and are:

1) Designed, optimized and validated Conceptual Adaptive Model of the System "Sensitive" to Workplace Changes,

2) A developed and validated model of water purification system that treats municipal waste water on the quality of water for human consumption and

3) Methodology has been established for the research of complex, engineering water purification systems.

\section{CONFLICT OF INTEREST}

The authors declare no conflict of interest.

\section{AUTHOR CONTRIBUTIONS}

Lovorka Gotal Dmitrović conducted the research and developed the mathematical and computer model; developed adaptive model and conducting the experiment; Hrvoje Selec data collection and analysed the data; developed conceptual models; Mario Lešina wrote the paper; all authors had approved the final version.

\section{REFERENCES}

[1] P. D. Allison, Missing Data, Sage University Papers Series on Quantitative Applications in the Social Science, 2001.

[2] J. Dobša et al., "Missing data problems in non-Gaussian probability distributions," Informatologia, vol. 49, pp. 3-4, 138-152, 2016.

[3] J. G. Ibrahim et al., "Missing-dana methods for generalised linear models: A comparative review," Journal of the American Statistical Association, 2005.
[4] R. J. A. Little, "A test of missing completely at random for multivariate data with missing values," Journal of the American Statistical Association, vol. 83, no. 404, pp. 1198-1202, 1988.

[5] V. Dušak et al., "The development of conceptual, mathematical and system dynamics model for food industry wastewater purifying system," JIOS, vol. 39, no. 2, pp. 151-162, 2015.

[6] B. Petz, V. Kolesarić, and D. Ivanec, Petzova Statistika, Naklada Slap, Zagreb, 2012.

Copyright @ 2019 by the authors. This is an open access article distributed under the Creative Commons Attribution License which permits unrestricted use, distribution, and reproduction in any medium, provided the original work is properly cited (CC BY 4.0).

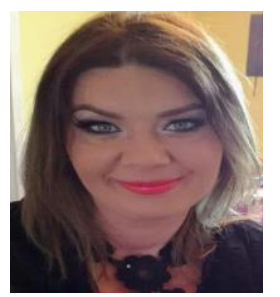

Lovorka Gotal Dmitrović was born in Varazdin, Croatia. She gained her degree on Faculty of Chemical Engineering and Technology, University of Zagreb, Croatia; the PhD degree is gained on Faculty of Organization and Informatics, University of Zagreb, Croatia.

She is assistant professor at University North, Croatia. She is actived in many scientific organisations. As the scientist, she deals with environmental informatics, simulation modelling, environmental protection and waste management.

Prof. Gotal Dmitrović is author of three books and 20 scientific articles in bibliographic database for academic journal articles.

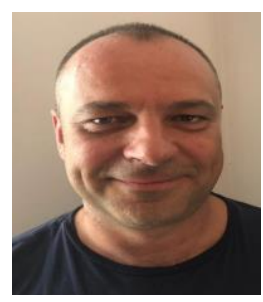

Mario Lešina was born on January 28. 1973, in Varazdin, Croatia. He gained his degree on Faculty of Economics in Zagreb, University of Zagreb, Croatia in 1996. The PhD degree is gained on Josip Juraj Strossmayer University in Osijek, Croatia in 2017.

One of the prominent Croatian entrepreneurs, active in many government and non-government organisations, including presidency of the special branch association in Croatian Chamber of Commerce, stake holding organisation in Croatia. As the scientist, he deals with economic history and growth models, and environment issues as well. Author of many articles on mentioned topics. Active in municipal politics according economic and environmental issues. Also teaches on University North Varaždin, Croatia.

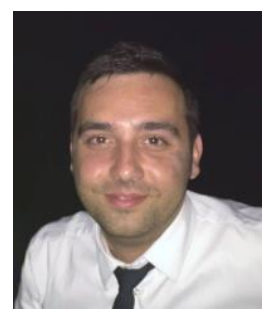

Hrvoje Selec was born on January 20. 1984, in Varazdin, Croatia. He has completed multimedia, design and application at University North, Croatia.

$\mathrm{He}$ is active in many non-government organisations in field of multimedia.

Mr. Selec is the executive producer of the Film-Creative Studio VANIMA and He is the festival director the VAFI International Animation Festival. 